\title{
Research on Practice Teaching for Web Page Design MOOC Xiao $\mathrm{Yu}$
}

\section{School of Information Engineering, Wuhan Technology and Business University, Wuhan, Hubei} Province, 430065

\begin{abstract}
This paper aims at the characteristic of the teaching of web page design and production course in higher education and analyzes this course on the platform of domestic MOOC. Problems and solutions to MOOC course teaching practice have been arisen. We have designed curriculum steps to deeply discuss experience and researches on teaching courses in the manner of MOOC.
\end{abstract}

Keywords: Mu class; Web page design and production; Practice teaching; New media; Flipped class

\section{网页设计慕课实践教学研究}

喻晓

武汉工商学院、信息工程学院, 湖北 武汉 430065

摘要：本文针对高校网页设计与制作专业课程教学实践的特点, 对国内慕课平台上的网页设计与制作课程进行了分析, 提出了慕课课程教学实践中遇到的问题和解决方法, 进行了课程环节的设计, 对慕课方式下课程教学的经验与探索进行了探 讨。

关键词: 慕课; 网页设计与制作; 实践教学; 新媒体; 翻转课堂

中图分类号: TM 344.1 文献标志码: A

\section{引言}

慕课对各种教育的人才培养方法、教学方式、管理模式等的再造带来 “破坏性的创新”，影响力巨大 [1-2]。EDX 总裁认为, 慕课已经显现 “未来教育的曙光” [3], 斯坦福大学校长甚至将慕课比作教育史 上的 “一场数字海啸” [4]采用慕课方式进行课程教学是教师提升教学水平的一个机遇。高校专业课程教 学要进行创新, 在教学实践中进行探索和总结经验, 利用新媒体不断优化课堂、积累教学资源、进一步完 善教学内容。

\section{1 慕课平台上的网页设计与制作课程}

网页设计与制作课程是新媒体学科、艺术设计学科和计算机学科的一门重要的专业课，也是一门注重 理论知识与实践应用相结合的课程。学生通过学习这门课程, 能够掌握网页页面的布局, 运用 HTML 语言 编写页面，灵活运用各种 CSS 样式美化页面，使用 JavaScript 语言设计页面效果，最终达到能够应用所 学的知识以某个主题来制作完整的静态网站的能力。在这门课程传统教学中, 采用的是多媒体教室课堂讲 授和计算机实验室上机相结合的方式。近几年来, 慕课不断的发展, 各大高校都尝试采用新的教学理念和 教学手段增加师生互动、提高教学的质量和效果, 以形成高校课程的特色。慕课（MOOC）这个术语是 2008 年由加拿大爱德华王子岛大学网络传播与创新主任与国家人文教育技术应用研究院高级研究员联合提出 来的。在百度百科中关于慕课的定义是从每个字母的含义进行解释的。所谓 “慕课”，顾名思义，“M” 代 表 Massive (大规模), 与传统课程只有几十个或几百个学生不同, 一门 MOOCs 课程动轩上万人, 最多达 16 万人; 第二个字母 “ 0 ” 代表 Open（开放), 以兴趣导向, 凡是想学习的, 都可以进来学, 不分国籍, 
只需一个邮箱, 就可注册参与; 第三个字母 “ 0 ” 代表 $0 n l i n e$ (在线), 学习在网上完成, 无需旅行, 不受 时空限制; 第四个字母 “C” 代表 Course, 就是课程的意思。慕课发展至今, 涌现了很多优秀的教育平台, 其中 Coursera 是最大的慕课平台, 拥有近 500 门来自世界各地大学的课程, 门类丰富, 不过也良莠不齐。 在中国公认比较有名的三个大的慕课平台, 分别是中国大学 MOOC, 学堂在线、好大学在线, 总共推出了一 百多门课程 [5]。

采用慕课教学可以分享到开放的、优秀的、权威的网络课程资源。截止 2016 年 10 月, 在各个大型慕 课网站上以 “网页设计与制作” 课程作为关键字进行搜索，其搜索结果只有三门课程与本校网页设计与制 作课程大纲的内容相似。在 Coursera 网站上的课程有伦敦大学的 “响应式网站基础：HTML、CSS 与 JavaScript” 和约翰霍普金斯大学的 “面向 Web 开发者的 HTML、CSS 与 JavaScript 课程”。国内三大慕课 网站上只有在学堂在线上有一门课程, 即由清华大学关琰副教授开设的 “界面设计导论”。慕课是最近 几年来教育领域出现的一种新的教学模式, 该模式颠覆了传统的以老师 “讲” 为主的教学模式, 并把课堂 延伸到课外 $[6-8]$ 。在国内外公认慕课平台上的这三门网页设计与制作课程都是著名大学教授开设的。 课程内容各具特色, 也各有侧重点。或是偏向于网站设计基础, 或是面向网页开发者的课程, 或是课程中 注重界面设计。它是通过一种方式方法让世界各地的学习者和授课者在共同的话题或主题下展开学习和应 用 [9]。但是, 慕课平台上的课程对于本校学生来说不是非常适合, 与本校网页设计与制作课程教学大纲 也不是非常吻合。因此，慕课平台上的这三门课程不能直接作为教学内容在课堂上应用。

\section{2 慕课方式下课程教学实践}

慕课方式下较难解决的问题主要是教学过程中师生互动的问题和教学内容针对性的问题 [10]。近两年 来, 我校组织了关于慕课教学的讲座和会议, 探讨慕课在高校教学中的实施问题, 还组织老师们参加多校 联合的慕课制作培训并开展了研讨会。但是, 目前为止, 慕课在各大高校专业性课程教学的实施中却很难 成为主要的教学方式。许多老师仍然认为制作和录制课堂过程的视频, 然后发布到网上, 这就是慕课教学。

\section{1 教学内容更有针对性}

慕课不仅是一种新媒体的教学方式，在教学实践中将改变教学的整个过程。在实践教学中提出了一种 教学方案对于本校学生的教学特点更具有针对性。在教学过程中, 首先教师在备课时参考慕课平台上的课 程资源, 选择与本校大纲内容相符合或相近的教学资料, 供学生课下扩展学习。其次, 教师设计配合慕课 教学的教学体系, 录制适合本校课程教学的视频, 最后制作课程资源内容上传到公共慕课平台。学生在学 习过程中，首先通过登录到授课教师的慕课平台上观看课程视频。幕课在进行下一问题时也会设置各种小 问题、小测验, 答对的学生可继续上课参与下一问题的探讨 [11]。可以通过移动终端或联网计算机进行在 线课程学习。其次需要阅读教材, 通过阅读纸质教材帮助学生巩固慕课所学的知识内容。每个模块学习都 安排了翻转课堂课时, 学生需要按照教学计划参加翻转课堂。在翻转课堂上, 学生分享学习的体会和提出 学习中的疑问, 教师组织同学们一起讨论并给予指导和解答。教师也可以事先录好视频或网络下载可供学 生课外观看, 这样教师可利用课堂时间解答学生的问题, 制定学生作业计划, 这使得学生能熟练掌握相关 知识和应用方法 [12]。课后, 学生在慕课平台上完成在线测试, 检查知识掌握程度, 完成综合页面设计, 并将作品上传。 


\section{2 线上线下教学增加师生互动}

课程采用慕课方式教学, 将改变传统教学方式。网页设计与制作课程的教学目标是让学生了解网页设 计与制作的流程, 学会使用网页开发工具, 掌握网页设计的样式, 能够进行网页制作, 为后续课程的应用 打下基础。在教学大纲中强化实践教学在课程教学中的比例, 增加上机实验课时。原先多媒体教室课堂讲 授的教学环节将拆分成慕课和翻转课堂相结合的方式。翻转课堂安排在计算机实验室, 增加了综合页面设 计的课时。这种线上线下相结合的方式既可以发挥慕课的优势, 又可以弥补慕课教学中师生互动不足的问 题。课程学时安排上进行了相应的调整。

表 1 网页设计与制作课程学时分配表

\begin{tabular}{ccccc}
\hline 序号 & 章节/专题/模块名称 & 慕课课时 & 翻转课堂课时 & 总课时 \\
\hline 1 & 第一模块 HTML & 8 & 6 & 14 \\
2 & 第二模块 CSS & 6 & 6 & 12 \\
3 & 第三模块 JavaScript & 6 & 6 & 12 \\
4 & 第四模块 综合页面设计 & 2 & 8 & 10 \\
总计 & & 22 & 26 & 48 \\
\hline
\end{tabular}

\section{3 慕课方式下课程教学经验与探索}

慕课方式下的网页设计与制作课程教学改革是一个不断探索和长期积累经验的过程。在教学的方式与 方法上还需要注意以下几个方面。

\section{1 教学环节}

在慕课方式下进行网页设计与制作课程的教学, 经常会发生有的学生在翻转课堂之前没有完成慕课平 台上的学习, 使教师的教学进度放慢或很难推进。因此, 在慕课教学中非常考验教师对课程和学生的把控 能力。教师在翻转课堂之前要监控网上学生在慕课平台上学习进度, 提前提醒学生完成慕课学习。未在翻 转课堂之前完成慕课学习的学生, 教师应在平时成绩评定时给予警告, 督促学生按时按进度完成每章学习 的内容。

\section{2 教师培训}

高校要做好慕课教学的师资培训, 其一要培训教师学会使用制作微课视频的工具, 其二要培训教师使 用慕课平台对学生的学习情况进行跟踪和反馈, 其三要培训教师在慕课方式下教学进度管理。

\section{3 考核方式}

由于慕课方式下的教学测试题在网上完成，学生之间可以通过线上线下的讨论来完成测试题和作品。 为了保证教学质量, 让学生真正掌握课程内容, 避免抄袭或代考现象, 网页设计与制作课程综合总评成绩 由平时成绩和期末作品成绩来组成。总评成绩为 100 分, 其中, 平时成绩占 40 分, 期末作品成绩占 60 分。 平时成绩的考核由慕课平台上每个模块测试题的得分和翻转课堂的表现来决定。期末作品成绩由慕课平台 上提交的网页作品得分和作品答辩表现来决定。教师和学生面对面的答辩能够检查学生是否认真完成了网 页设计的任务。 


\section{4 慕课平台}

慕课平台的建设需要不断更新课程内容并配合教学改革发展而不断完善。慕课平台上的教学资料形成 的大数据, 对改进教学方法, 分析教学中的问题非常有帮助。为了慕课方式下的高校教学改革更加深入, 慕课平台应该分为两个部分: 一个部分是面向社会的公共平台; 一个部分是面向高校的教学管理辅助平台。 对外的慕课平台可以支持多种方式登录慕课, 本校学生或互联网上的公众都可以通过汶览器打开网站直接 登录, 也可以通过微信公众号登录。对内的慕课教学辅助管理平台是为了高校教师开设本校慕课课程而对 本校学生进行教学管理的平台。教师在辅助管理平台上可以上传本校课程的教学目标和要求, 并查看和跟 踪学生选课信息和学习进度等。

\section{4 结语}

2016 年国家十三五规划纲要的第五十九章中提出“推动现代信息技术与教育教学深度融合”。在当 今信息技术发展日新月异的时代, 如何加强新媒体技术与高校课堂教学真正达到深度融合是教学改革需要 思考的问题。在网页设计与制作课程教学实践中进行了一些探索与尝试，对新媒体技术更好的引入到传统 专业性课堂教学中提出了一些思路, 得到了一些体会, 进行了一些探讨。

\section{参考文献:}

[1] 贺洪丽，杨曼. 慕课的实践困惑及反思 [J]．现代教育科学，2016，（12）：124-125.

[2] 顾小清, 胡艺龄, 蔡慧英. MOOCs 的本土化诉求及其应对 [J]. 远程教育杂志, 2013，(5)：3-11.

[3] 李曼丽, 张羽, 叶赋桂, 等. 解码 MOOC: 大规模在线开放课 程 的教 育 学 考察 [M]. 北京: 清华大学 出版 社, 2013: 138.

[4] 吴剑平，赵可．大学的革命：MOOC 时代的高等教育 [M]. 北京：清华大学出版社，2014：53.

[5] 樊林君. 慕课给新闻传播教学带来的机遇与冲击 [J]。青年记者，2015，(14)：84-85.

[6] 唐 琼, 徐玉辉, 张振文。慕课在网页设计课程教学中的应用 [J], 湖北第二师范学院学报, 2016, 33 (7) : 106-108.

[7]张琳．慕课视角下网页设计课程的教学生态模式研究 [J]。电脑知识与技术，2015，11(21)：129-130.

[8]王亮. 浅谈慕课背景下计算机网页设计课程的教学改革 [J]. 智富时代，2015，(7)：216.

[9] 刘志军, 冯永华. 课堂教学变革的反思与重建—— “慕课”背景下课堂教学变革的思考 [J]. 教师教育学报, 2014, $11(3): 53-63$.

[10］代玲玲，倪万. MOOC 方式下的数据新闻教学 $[J]$. 青年记者, 2016, (20)：116-117.

[11］孙晓娟. 基于 “慕课” 的高职课程改革及教学评价的研究 [J]. 中国管理信息化，2016，1 (4)：236-237.

[12］张琳．高职网页设计课程的教学生态模式研究 [J]．教育现代化，2015，4（10)：99-101.

\section{References}

[1] He Hongli, Yang Man. Practical Perplexity and Reflection on the Mu Class [J].Modern Education Science, 2016, (12):124-125.

[2] Gu Xiaoqing, Hu Yiling, Cai Huiying. Localization Appeal and Countermeasures of MOOCs [J].Journal of Distance Education, 2013, (5):3-11.

[3] Li Manli, Zhang Yu, Ye Fugui, etc. Decoding MOOC: Pedagogy Investigation on Massive Open Online Courses [M].Beijing: Tsinghua University Press, 2013: 138.

[4] Wu Jianping, Zhao Ke. University Revolution: Higher Education in MOOC Times [M].Beijing: Tsinghua University Press, 2014: 53. 
[5] Fan Linjun. Opportunity and Impact Brought by Mu Classes on Teaching of Journalism and Communication [J]. Youth Journalist, 2015, (14):84-85.

[6] Tang Qiong, Xu Yuhui, Zhang Zhenwen. Application of Mu Class in Teaching Courses of Web Design [J], Journal of Hubei University of Education, 2016, 33(7):106-108.

[7] Zhang Lin. Study on Teaching Ecological Model in Web Design Course From Perspective of Mu Class [J].Computer Knowledge and Technology,2015,11(21):129-130.

[8] Wang Liang. Teaching Reform of Web Design Courses under background of Mu Class [J].The Fortune Times, 2015, (7):216.

[9] Liu Zhijun, Feng Yonghua. Reflection and Reconstruction of Classroom Teaching Reform-Thoughts On Classroom Teaching Reform under Background of "Mu Class" [J].Journal of Teacher Education,2014,11(3):53-63.

[10] Dai Lingling, Ni Wan. Data Journalism Teaching in Mode of MOOC [J].Youth Journalist, 2016, (20):116-117.

[11] Sun Xiaojuan. Research on Curriculum Reform in Higher Vocational Education and Teaching Evaluation Based on "Mu Class" [J].China Management Informationization, 2016, $1(4): 236-237$.

[12]Zhang Lin. Study on Teaching Ecological Pattern of Web Design Course in Higher Vocational Education [J].Education Modernization,2015,4(10):99-101. 